\title{
Nanocarrier-based immunotherapy in cancer management and research
}

REVIEW

This article was published in the following Dove Press journal:

ImmunoTargets and Therapy

26 June 2014

Number of times this article has been viewed

\author{
Manu Smriti Singh' \\ Sangeeta Bhaskar ${ }^{2}$ \\ 'Laboratory of Pharmaceutical \\ Technology and Biopharmaceutics, \\ University of Bonn, Bonn, Germany; \\ ${ }^{2}$ Product Development Cell, National \\ Institute of Immunology, New Delhi, \\ India
}

Video abstract

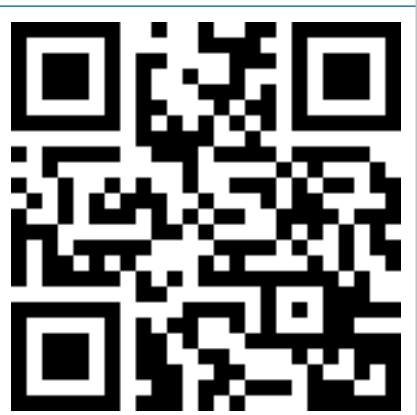

Point your SmartPhone at the code above. If you have a QR code reader the video abstract will appear. Or use: http://dvpr.es/lIGldgg
Correspondence: Sangeeta Bhaskar Product Development Cell, National Institute of Immunology, Aruna Asaf Ali Marg, New Delhi II 0067, India

Tel +9 I I I 26703670

Fax+9| II 26162125

Email sangeeta@nii.ac.in

\begin{abstract}
Research in cancer immunotherapy has gained momentum in the last two decades, with many studies and clinical trials showing positive therapeutic outcomes. Immunotherapy can elicit not only a strong anticancer immune response which could even control metastases, but could also induce immunological memory, resulting in long-lasting protection in the prophylactic setting and protection against possible recurrence. Nanocarriers offer an attractive means for delivery of a multitude of therapeutic immunomodulators which are readily taken up by immune cells and can initiate a particular arm of an immunostimulatory cascade leading to tumor cell killing. This review focuses on recent advances in nanocarrier-mediated immunotherapy for the treatment of cancer. Both in vitro and in vivo studies as well as clinical progress are discussed in various sections. Description of the specific role of nanoparticle technology in immunotherapy highlights the way particles can be tailor-made in terms of size, structure, payload, and surface properties for active targeting to antigen-presenting cells and/or enhanced accumulation in the solid tumor.
\end{abstract}

Keywords: cancer, immunotherapy, nanocarriers

\section{Introduction}

Immunotherapy refers to treatment of disease by manipulating the patient's immune system in order to alleviate the ailment. Immunotherapy may be categorized as activation or suppression immunotherapy on the basis of whether it induces or suppresses an immune response. Conditions such as chronic inflammatory bowel disease, allergy, or organ transplant rejection occur because of overreaction of the immune system necessitating immunosuppressive immunotherapy. On the other hand, cancer cells are not recognized by immune system, and immunotherapy in this case aims at activating the immune cells in the vicinity of a growing tumor to facilitate the recognition and elimination of tumor cells. The tumor microenvironment is generally suppressed due to the presence of inhibitory cytokines, ligands, and immunosuppressive cells, ie, myeloid-derived suppressor cells and T-regulatory cells. ${ }^{1}$ There has been considerable progress in cancer immunotherapy in the areas of adoptive immunotherapy, ie, manipulation of natural killer cells, lymphokine-activated killer cells, activating tumor-infiltrating lymphocytes, and dendritic cell (DC)-based autologous vaccines. ${ }^{2}$ Targeted therapies are being explored with the advent of recombinant DNA technology and molecular biology. These may act by activating or blocking a certain arm of the biological pathway and ultimately lead to tumor regression. Combination therapies such as chemoimmunotherapy are considered a multipronged strategy to control the growth of cancer cells. ${ }^{3}$ 
This review covers cancer immunotherapy, with special focus on the nanocarrier system-based targeted approach for cancer. It is divided into two sections, ie, prophylaxis and therapeutic immunotherapy. A detailed analysis of a number of studies, with respect to underlying principles of immunology, is provided. In the last section, clinical utility, the success achieved so far, and nanocarrier-based immunotherapies undergoing clinical trials are highlighted.

\section{Immunotherapy as a therapeutic strategy in cancer}

Cancer is characterized by unregulated proliferation of aberrant cells. Currently used treatments for cancer include chemotherapy, radiotherapy, and surgery, with variable efficacy depending on the type of cancer. Chemotherapy in conventional form targets all proliferating cells indiscriminately, killing both tumor and healthy cells. Both radiotherapy and surgery fail to combat metastases. Limitations of conventional cancer therapeutics have called for development of more effective and less harmful therapies. Tumor immunotherapy or vaccines are an attractive alternative. These are based on manipulating the patient's own immune system to recognize and destroy cancer cells. ${ }^{2}$ The advantages of cancer immunotherapy include its ability to induce specific killing of tumor cells with minimal damage to healthy cells, induce a systemic antitumor immune response that can control metastases, and induce immunological memory which could provide long-term protection against recurrence of a tumor in future.

One branch of immunotherapy aims to stimulate key players of the immune system. Tumors evade the immune response by scaling down major histocompatibility complex (MHC) I expression, thereby bypassing cytotoxic T-lymphocyte (CTL)-mediated tumor clearance. ${ }^{4}$ With the discovery of tumor-associated and tumor-specific antigens, many antitumor immunization possibilities are being explored. Whole tumor lysates are also being investigated as a source of antigen. ${ }^{5} \mathrm{~A}$ combination of antigen-adjuvant is the classical immunotherapy that has been explored for increasing APC (antigen-presenting cell)-aided CTLmediated tumor killing (Figure 1A). Enhancing costimulatory signaling for T-cell activation, proinflammatory cytokines, and antibody-mediated therapy all aim at increasing the intensity of the immune response against tumor cells (Figure 1A and D).

Another branch of immunotherapy aims at modulating the immune response by eliminating or suppressing the activity of immune cells that suppress CTLs such as myeloid-derived suppressor cells or forkhead box P3 T-regulatory cells (Figure 1E). ${ }^{6}$ Chemotherapy, because of indiscriminate killing, also results in depletion or inactivation of CD4+CD25+ T-regulatory cells, and thereby triggers homeostatic proliferation of T-cells. It is generally known that chemotherapyinduced cancer cell death results in production of large volumes of tumor antigens (Figure 1B) that are capable of mounting an effective immune response and eliminating CTLs. ${ }^{7}$ Chemotherapy administered at ultralow dose (termed chemoimmunomodulation) has demonstrated enhanced immunogenicity for malignant cells, ie, improved recognition by natural killer cells and activation of macrophages, DCs, and CTLs. ${ }^{8,9}$ However, as Shurin et $\mathrm{al}^{8}$ point out, it is difficult to explain why some drugs display opposite effects on different immune cells, ranging from functional stimulation to induction of apoptosis. Hence, chemotherapy remains the classical choice for overcoming immunosuppression in the tumor milieu, but again great forethought must go into optimization of the correct dose and schedule of chemotherapy so as not to suppress effector CTLs.

DCs are key players in an effective antitumor immune response and can be manipulated in different ways to enable them to prime tumor-specific T-cells. This can be done by ex vivo loading of DCs with tumor antigens, injection of irradiated tumor cells to be phagocytosed by DCs in vivo, antibody/ligand-mediated DC targeting, or chemotherapyinduced tumor antigen production. All these strategies lead to antigen capture by DCs, their subsequent processing, and presentation by MHC I and II molecules for stimulation of CD8+ and CD4+ T-cells, which in turn can induce tumor regression (Figure 1B and C). With the advent of a number of immunomodulators and nanocarrier-based delivery systems, targeting of tumorigenic pathways with even higher specificity as compared with conventional immunotherapy seems promising in the fight against cancer.

\section{Role of nanocarriers in immunotherapy}

Development of nanocarriers carrying various immunomodulators (Toll-like receptors [TLR] ligands/tumor-associated antigens/ligands [antibody] Figure 2) is underway, with many promising results so far. These formulations carrying a single immunomodulator or a combination of these have been used in several key pathways for cancer immunotherapy (Figure 1) with the primary aim of enhancing a specific immune response to cancer. ${ }^{10}$ These carrier systems are versatile in that they can simultaneously codeliver adjuvants with antigens to enhance activation and maturation of APCs, which can in 


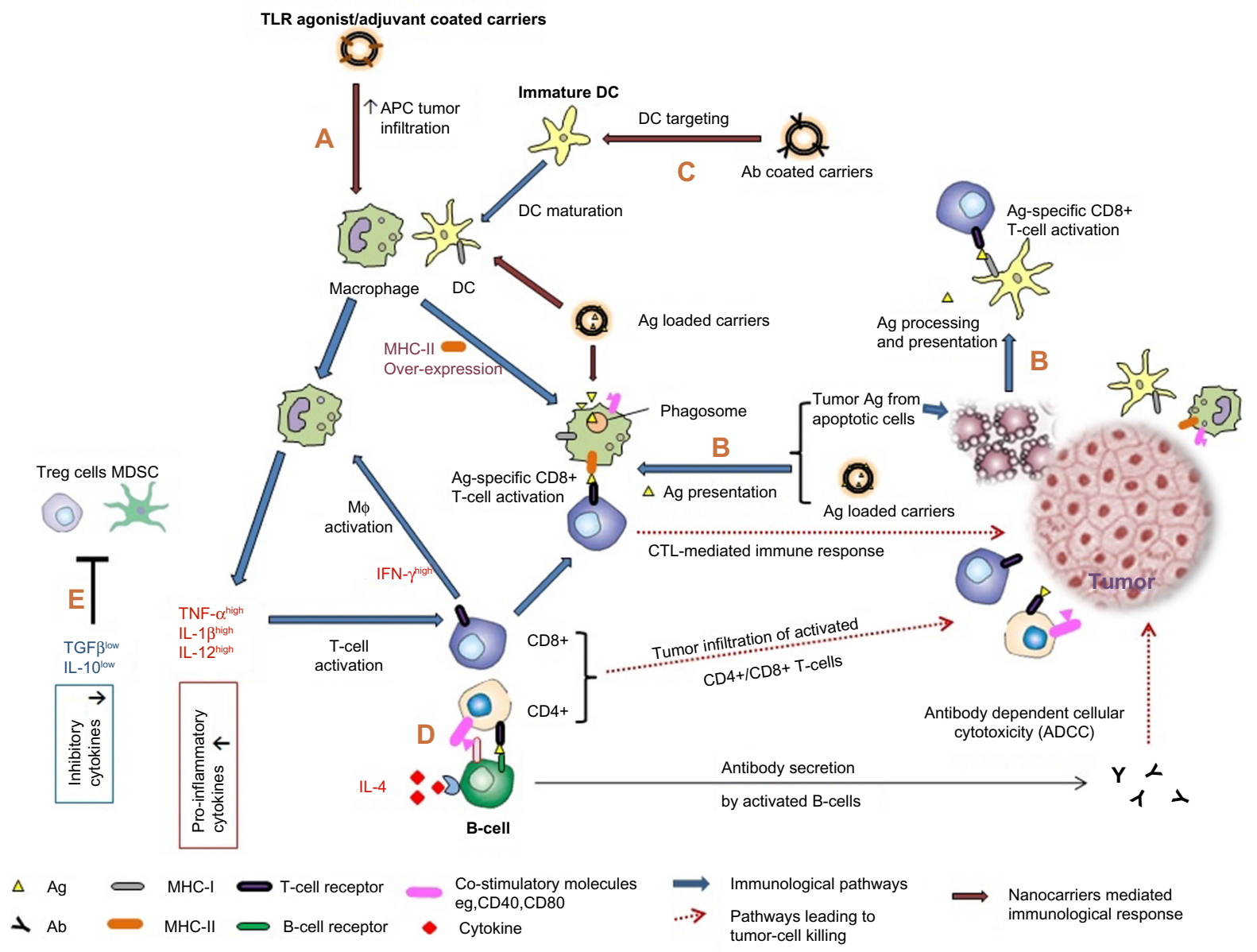

Figure I (A) Enhanced APC tumor infiltration, macrophage activation, and cytokine secretion following administration of adjuvant/TLR agonist-coated nanocarriers. (B) Agloaded nanocarriers and apoptotic cells are two sources of antigenic peptides. Antigen processing and presentation of these by APCs (DCs and macrophages) leads to T-cell activation and cytotoxic T-cell mediated tumor killing. Tumor infiltration of CD4+ and CD8+ T-cells has been shown to be a marker of tumor regression. (C) Antibodyspecific or ligand-specific DC targeting results in enhanced Ag presentation and DC maturation. (D) CD4+ T-cells provide help for B-cell activation. Together with cytokine stimulation, B-cells mature as plasma cells to secrete Ag-specific antibodies which mediate ADCC. (E) Reduction in MDSCs and T-regulatory cells.

Abbreviations: Ab, antibody; Ag, antigen; APC, antigen-presenting cells; CTL, cytotoxic T-lymphocytes; DC, dendritic cells; IFN, interferon; IL, interleukin; MHC, major histocompatibility complex; MDSC, myeloid derived suppressor cells; TGF $\beta$, transforming growth factor beta; Treg, regulatory T-cells; TLR, Toll-like receptor; TNF- $\alpha$, tumor necrosis factor alpha; $M \phi$, macrophage.

turn generate an antigen-specific CTL response and subsequent tumor regression. ${ }^{11}$ Two major vaccine constituents, ie, antigens and adjuvants (peptides, proteins, nucleic acids, oligonucleotides), can be codelivered as biocompatible, biodegradable, nanosized formulations to organs (lymph node/ spleen) or APCs due to their unique physicochemical properties. Additionally, nanocarriers can be designed to target the tumor, resulting in accumulation of tumor-specific antigens and adjuvants in the tumor microenvironment. Controlled release of these nanocarriers in the tumor milieu leads to development of a long-term memory response. Further, these delivery systems can address issues like solubility, poor bioavailability, and low therapeutic indices of antitumor effector molecules (eg, drugs, genes) following systemic administration. Various polymer-based (nanoparticles, nanomicelles), lipid-based (liposomes, nanoemulsions), and inorganic (metal oxide-based) nanocarrier systems are being developed to deliver multiple therapeutic moieties.

The role of the size of these particulate carriers in activating various immune cells is of great interest. In one study, $25 \mathrm{~nm}$ and $100 \mathrm{~nm}$ ovalbumin-conjugated polyhydroxylated nanoparticles were tested as vaccine candidates in a mouse model. ${ }^{12}$ Unlike bigger particles, these smallsized nanoparticles when injected intradermally into mouse dorsal foot skin were transported efficiently to draining lymph nodes via lymphatic capillaries, and activated the complement system. They induced DC maturation and CD8+ T-cell activation in lymph nodes, comparable with that seen when ovalbumin is coinjected with lipopolysaccharide (LPS). The antibody titers were found in serum up to 21 days post vaccination. This study demonstrated the importance of lymph node DC targeting, together 
TLR-ligands (Adjuvants)

-TLR3-poly I:C (polyinosinic: poly cytidylic acid)

- TLR4-lipopolysaccharide (LPS) and monophosphoryl lipid A (MPLA)

- TLR9-unmethylated CpG motifs

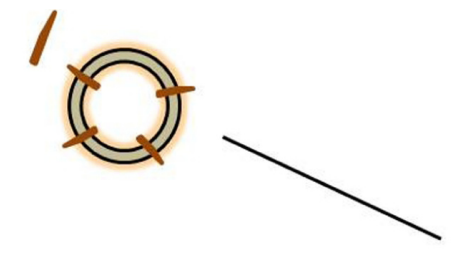

Tumor associated antigens (TAA)

- Ovalbumin (OVA)

- MUC1 lipopeptide (BLP25)

- Carcinoembryonic antigen (CEA)

- TRP2/ hgp100/ MAGE
(TAA)
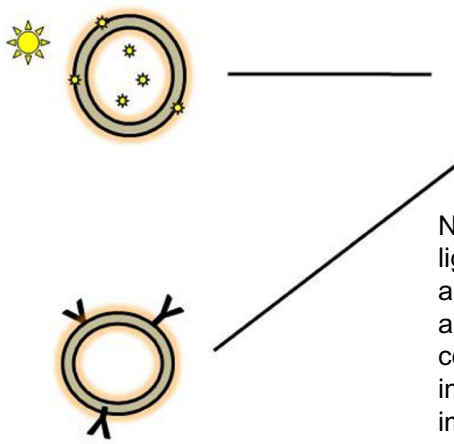

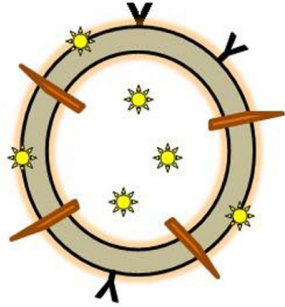

Nanoparticles carrying TLRligands (adjuvants), tumor associated antigen or antibody (alone or in combination) are under investigation for cancer immunotherapy

Figure 2 Nanocarriers under investigation in cancer immunotherapy Abbreviations: TLR, Toll-like receptor; DC, dendritic cells; $\mathrm{T}_{\text {reg }}$, regulatory T-cells; MAGE, melanoma-associated antigen.

with complement activation which could induce both the humoral and cellular arms of immunity.

Cancer vaccines are being evaluated in both the prophylactic and therapeutic settings. Prophylactic vaccination aims at generating cancer-specific antibodies or memory T-cells against possible future challenge by cancer-specific antigens. On the other hand, therapeutic vaccination is given following the onset of disease and aims at activation of macrophages and DCs, and in turn, expansion of cancer-specific CD8+ CTLs which eventually lead to death of cancer cells. In the following section, we discuss a few important nanoparticle-based vaccination strategies that have shown promising outcomes.

\section{Prophylactic immunotherapy}

Prophylactic immunization aims to elicit antitumor immunity and long-term memory without inducing autoimmunity. High-risk individuals with a genetic predisposition to certain types of cancer could be considered for prophylactic immunization. Analogous to immunization against various infectious diseases, vaccines providing protective immunity against virally induced cancers such as human papillomavirus or hepatitis B virus, are under investigation. Virus-like particles are self-assembly of viral capsid and resemble viruses but are noninfectious. Recently, virus-like particle-based vaccines against hepatitis B virus (Engerix ${ }^{\circledR}$; GlaxoSmithKline plc, London, UK) and human papillomavirus (Cervarix ${ }^{\circledR}$; GlaxoSmithKline plc, and Gardasil ${ }^{\circledR}$; Merck \& Co., Inc., Whitehouse Station, NJ, USA) have been approved and commercialized for prophylactic vaccination. ${ }^{13}$
Other virally induced cancers, such as those caused by Epstein-Barr virus or herpes virus (Kaposi sarcoma), can similarly be addressed using nanocarriers or virus-like particle-based vaccination.

Since the early 1990s, a number of antigens overexpressed on human cancers have been characterized, and the conspicuous presence of these tumor-associated antigens could be recognized by immune cells. A common feature of many particle-based preparations is the use of these characterized tumor-associated antigens or whole cell tumor lysate ${ }^{14}$ as a source of antigenic peptides. While some have been tested in the prophylactic setting, others have evaluated their therapeutic efficacy with respect to cancer immunotherapy. Vaccines composed of adjuvant together with tumor-associated antigen peptides $^{15}$ are being evaluated. Sustained antigen release from these nanocarriers alleviates the need for a prime boost because strong protection is provided by a single injection. Different drug delivery systems such as liposomes ${ }^{16}$ and nanoparticles ${ }^{5,17}$ containing these tumor-associated antigens have been tested in animal models for their prophylactic potential against cancer (Table 1). In spite of the development of several prophylactic strategies to target cancer, mainly virally induced cancers, it seems difficult to contain the disease by a prophylactic strategy due to the complex nature of the disease, the plasticity of tumor cells, and their ability to "immunoedit" the tumor microenvironment. Moreover, the presence of the normal self-antigen on the tumor surface makes it difficult for immune cells to recognize them as altered self-cells. 
Table I Prophylactic nanocarrier-based immunotherapy

\begin{tabular}{|c|c|c|}
\hline Nanocarrier system & Outcome of study & Reference \\
\hline $\begin{array}{l}\text { Liposomes prepared from tumor-derived PMV } \\
\text { carrying antigenic peptide ovalbumin and coated } \\
\text { with single chain antibody (anti-DEC-205) for DC } \\
\text { targeting. }\end{array}$ & $\begin{array}{l}\text { Two-fold better protection against tumor challenge } \\
\text { when liposomes with LPS/IFN- } \gamma \text { as costimulators were } \\
\text { administered. Antitumor response and prolonged } \\
\text { disease-free survival were observed in mice. }\end{array}$ & van Broekhoven et al ${ }^{16}$ \\
\hline $\begin{array}{l}\text { Murine melanoma peptides (HGP and TRP) and } \\
\text { TLR-4 agonist MPLA codelivered in PLGA NPs. }\end{array}$ & $\begin{array}{l}\text { Delayed growth of subcutaneously inoculated BI6 } \\
\text { melanoma cells. }\end{array}$ & Zhang et al ${ }^{17}$ \\
\hline $\begin{array}{l}\text { ISAP loaded with low-dose cyclophosphamide or } \\
\text { anti-CD25 (for suppression of Tregs), tumor lysate, } \\
\text { and CpG oligonucleotide. }\end{array}$ & $\begin{array}{l}\text { Complete Ag-specific immunity was attained in } \\
\text { prophylactic model. }\end{array}$ & Goforth et $\mathrm{al}^{5}$ \\
\hline $\begin{array}{l}\text { ICMV-based liposomes with } \mathrm{Ag} \text { in their core and } \\
\text { MPLA engrafted on the envelope. }\end{array}$ & $\begin{array}{l}\text { Codelivery of Ag-TLR ligand to APCs showed strong } \\
\text { Ag-specific CTL response, persistence of memory } \\
\text { cells, and } \uparrow \text { IFN- } \gamma \text { secretion by T-lymphocytes. }\end{array}$ & Moon et $\mathrm{al}^{18}$ \\
\hline $\begin{array}{l}\text { Melanoma-derived Ags were introduced into DCs by } \\
\text { perfluoropropane gas-entrapping bubble liposomes } \\
\text { and ultrasound. These preconditioned DCs were } \\
\text { used for prophylactic immunization of mice. }\end{array}$ & $\begin{array}{l}\text { Four-fold reduction in lung metastasis, showing aBI6/ } \\
\text { BL6-specific antitumor immune response. }\end{array}$ & Oda et al ${ }^{19}$ \\
\hline $\begin{array}{l}\text { OVA-Ag coated poly- } \alpha \text {-hydroxy acid-based } \\
\text { microparticles used in heterologous prime boost } \\
\text { vaccinations (similar to adenovirus vectors). }\end{array}$ & $\begin{array}{l}\text { OVA-specific CD8+ T-cell generation and } \\
\text { subsequent protection from further tumor challenge. } \\
\text { Considerable prophylactic efficacy (more than } \\
\text { therapeutic efficiency) reported in mice. }\end{array}$ & Lemke et $\mathrm{al}^{20}$ \\
\hline $\begin{array}{l}\text { Fusogenic liposomes carrying tumor cell lysate } \\
\text { displaying accessory proteins from Sendai virus } \\
\text { (for retaining membrane fusion ability). }\end{array}$ & $\begin{array}{l}\uparrow \text { APC uptake and cross-presentation. Ex vivo DC- } \\
\text { mediated immunization strategy; however, gave better } \\
\text { results than direct immunization in murine BI6/BL6 } \\
\text { melanoma model. }\end{array}$ & Yoshikawa et $\mathrm{al}^{21}$ \\
\hline
\end{tabular}

Abbreviations: Ag, antigen; APC, antigen-presenting cell; DC, dendritic cell; OVA, ovalbumin; PMV, plasma membrane vesicles; MPLA, monophosphoryl lipid A; ISAP, immune-stimulatory antigen-loaded PLGA NPs; PLGA, poly(lactic-co-glycolic acid); NPs, nanoparticles; ICMV, interbilayer-crosslinked multilamellar vesicles; IFN- $\gamma$, interferon gamma; LPS, lipopolysaccharide; TLR, Toll-like receptor; TRP, tyrosinase-related protein HGP, human glycoprotein.

\section{Therapeutic immunotherapy}

Researchers have realized that anticancer vaccines need to be therapeutic more often than prophylactic. Therapeutic vaccines are given after the onset of disease and aim at delaying growth, controlling metastases and disease relapse, or killing cancerous cells altogether. APCs, primarily DCs, are the main effectors in immune stimulation against cancer. DCs in the tumor microenvironment can be targeted to reprogram tumor-promoting inflammation towards tumor killing mode. DC-specific antibodies fused with cancer-specific antigens along with DC activators result in potent antigen-specific CD4+ and CD8+ T-cell-mediated immunity. ${ }^{22}$ Once a cellmediated immune response is induced, cytokines (interferon gamma [IFN- $\gamma]$ and tumor necrosis factor alpha $[$ TNF- $\alpha]$ ) and chemokines along with contact-mediated cytotoxicity lead to death of cancer cells. Many of the nanoparticle/liposome formulations carry tumor-specific antigens together with targeting moieties, such as antibodies and immunomodulators, to enable activation of APCs, mainly DCs. Due to their particulate nature and dimensions, nanoformulations are readily taken up by DCs, eliciting a T-cell and antibody response..$^{23}$ In most therapeutic immunization strategies, DCmediated antigen-specific CTL responses ultimately lead to tumor regression. ${ }^{24}$ In the next section, we enumerate some of the formulations with therapeutic potential (Table 2). The section is subdivided based on the cargo (antigen/antibody/ TLR ligand/cytokines, see Figure 1) these formulations are tailored to carry.

\section{Adsorption versus encapsulation of antigens in a nanocarrier system}

Formulations carrying antigens have demonstrated an ability to induce tumor regression in animal models in the therapeutic setting. ${ }^{25-28}$ Their mode of action differs depending on the presence of antigens on the surface of nanoparticles or their encapsulation within the particle core. Encapsulation, unlike adsorption, leads to sustained release of antigen, resulting in prolonged antigen presentation on APCs, ultimately inducing higher T-cell activation. ${ }^{29}$ Hepatitis $\mathrm{B}$ surface antigen encapsulated in PEGylated poly(lactic-co-glycolic acid) (PLGA) nanoparticles (150-200 nm) was shown to promote rapid uptake and localization in the endosome. Vaccination with these nanoparticles led to high titers of antigen-specific antibodies.

By chemically conjugating antigen on NP surface, nanocarriers can be made to mimic pathogens resembling not only 
Table 2 Therapeutic nanocarrier-based immunotherapy

\begin{tabular}{l} 
Nanocarrier system \\
\hline Antigen-loaded NPs \\
Layer-by-layer-assembled disulfide cross-linked PMA ${ }_{\mathrm{SH}}$ \\
hydrogel encapsulating OVA
\end{tabular}
hydrogel encapsulating OVA

CEA conjugated to inorganic iron oxide-zinc oxide $\left(\mathrm{Fe}_{3} \mathrm{O}_{4}-\mathrm{ZnO}\right)$ core-shell NPs

Whole cell lysate derived from patients with head and neck squamous cell carcinoma encapsulated in PLGA NP Polymer-modified OVA-loaded liposomes which become highly unstable below $\mathrm{pH} 6$ at which OVA can be released directly in endosomes

Cytokine-loaded NPs

IL-I-loaded NPs infused onto T-cells ex vivo and reintroduced in mouse tumor

PBCA NPs loading TGF- $\beta$ antisense ODN used to treat glioblastoma brain tumor in Fischer rats

Adjuvant/immunostimulant-coated NPs Ultrasmall gold NPs conjugated with CPG ODN, $15 \mathrm{~nm}$ in diameter, compared with administration of $C_{p G}$ alone Immunostimulatory peptide ( $\mathrm{Hp}$ 9l) derived from an endogenous protein (HMGBI) encapsulated in or conjugated on the surface of PLGA NPs

Ab/ligand-coated NP for active targeting NPs (developed from polyethyleneimine and C32 (poly( $\beta$-amino ester)) encasing TLR agonists ( $C_{p} G$ or poly I:C) and a plasmid (pSP-D-CD40L)-expressing CD40 ligand

OVA encapsulated PLGA NPs with lipid-PEG complexed with humanized targeting Ab hDI (DC-restricted CLRDC-SIGN). NPs were coencapsulated with poly (I:C) and resiquimod (R848) as adjuvants

NPs with combination of immunomodulator and drug P-LPS and PTX coencapsulated in PLGA NPs

Doxorubicin-loaded NPs were developed using an immunotherapeutic self-organizing AcFu polymer

Ad-Ag codelivery with particle-based carriers OVA and poly (I:C) or CPG coadministered in microspheres compared with incomplete Freund's adjuvant

OVA and poly (I:C) or CPG coadministered in PLGA microspheres

OVA and poly (I:C) conjugated with CTAB and coencapsulated in $\mathrm{pH}$-sensitive polyketal (PK3) microparticles

Coencapsulation of MPLA with either of Ag-OVA or BLP25
Outcome of study

Reference

OVA-PMA $_{\mathrm{SH}}$ hydrogel internalization by mouse APC resulted in OVA specific CD4+ and CD8+ T-cells. Following intravascular vaccination of mice, CD4+ and CD8+ T-cells showed 6-fold and 70-fold higher activation respectively as compared with equivalent amount of OVA administered alone

These NPs enabled real-time monitoring by magnetic resonance imaging. Mice immunized with NP-Ag-treated DCs demonstrated enhanced CTL-mediated responses, thereby delaying tumor growth and increasing survival rates

Ag-loaded NP delivered to patient-derived DCs led to stimulation of CD8+ T-cells. $\uparrow$ IFN $\gamma$ and $\downarrow$ IL-10 observed in $80 \%$ of patients OVA-specific CTL response led to reduction in tumor burden in E.G7-OVA tumor-bearing mouse model

$\uparrow \mathrm{T}$-cell proliferation and survival within tumor, thus amplifying the antitumor response as compared with systemic cytokine administration

$\downarrow$ TGF- $\beta$ levels, $\uparrow$ activated CD25+ T-cells. Survival rates higher in NP-immunized rats than im untreated rats

Sexton et $\mathrm{al}^{25}$

Cho et $\mathrm{a}^{26}$

Prasad et $\mathrm{al}^{27}$ Yuba et a ${ }^{28}$

Enhanced CPG macrophage stimulation

High infiltration of DCs and macrophages at tumor site, resulting in tumor inhibition and prolonged survival in mice

When encapsulated in or conjugated on the surface of NP, Hp-9l was found to be 5 -fold and 20 -fold more potent, respectively, than in the free form. Due to their DC-activating potential, Hp-9I-NPs are promising delivery vehicles for treatment of cancer

CD40L and TLR agonist act synergistically, resulting in tumor-free survival in NP-treated groups versus control

DC-specific antibody/ligand-coated carriers achieved active targeting to DCs. NP induced CTL responses at 100 -fold lower dose of adjuvant than that administered in soluble form in mice

Mean tumor volume of TLNP-treated mice was found to be $40 \%$ less than in animals treated with PTX and P-LPS alone. Higher infiltration of APCs (macrophages and DCs) and T-cells was observed in the tumor microenvironment

AcFu-NP-potentiated secretion of TNF- $\alpha$ and GM-CSF in Raw264.7 macrophages

Single vaccination in mouse models of EG-7 thymomas and MO-5 melanomas resulted in high titers of OVA-specific $\lg G I$ and $\lg$ G2a and CTL-mediated killing for up to 21 days post-immunization Eight-fold higher IFN- $\gamma \mathrm{CD} 8+\mathrm{T}$-cell than control in melanoma mice models following single immunization

Secretion of IL-2 by CD8+ T-cells enhanced by more than 6-fold. $30 \%$ and $25 \%$ higher secretion of cytokines TNF- $\alpha$ and IFN- $\gamma$, respectively, as compared with control groups Maturation of DCs was enhanced when induced by MPLA in PLGA NP compared with induction in soluble form. MPLA coadministered with Ag lead to $\uparrow$ proinflammatory IL-6, IL- I2, and TNF- $\alpha$ cytokine expression, and $\downarrow$ IL- I 3 and IL- 4 expression
Stone et $\mathrm{al}^{37}$

Tacken et $\mathrm{al}^{38}$

\section{Stephan et $\mathrm{al}^{33}$ \\ Schneider et $\mathrm{al}^{34}$ \\ Lin et $\mathrm{al}^{35}$ \\ Clawson et $\mathrm{al}^{36}$}

Roy et $\mathrm{a}^{39}$

Woo et $\mathrm{al}^{40}$

Mueller et al ${ }^{41}$

Schlosser et $\mathrm{al}^{42}$ Heffernan et $\mathrm{al}^{43}$

Elamanchili et al ${ }^{44}$ 
Table 2 (Continued)

\begin{tabular}{|c|c|c|}
\hline Nanocarrier system & Outcome of study & Reference \\
\hline $\begin{array}{l}\text { Acid-degradable hydrogel coencapsulating OVA and } \\
\text { CpG }\end{array}$ & $\begin{array}{l}\uparrow \text { Ag-specific T-cells and greater survivability of mice upon } \\
\text { therapeutic immunization. Ag-specific T-cells demonstrated } 20 \% \\
\text { higher efficacy in lysing target cells in the OVA-CpG-NP treatment } \\
\text { groups as against OVA-NP administered with CpG in soluble form }\end{array}$ & $\begin{array}{l}\text { Beaudette } \\
\text { et } \mathrm{al}^{45}\end{array}$ \\
\hline $\begin{array}{l}\text { Gold NPa coated with RFP (as model Ag) and CpG } \\
\text { evaluated in RFP-expressing melanoma tumor models }\end{array}$ & $\begin{array}{l}\text { Lymph node targeting resulted in interaction of NPs with DC } \\
\text { inducing potent CTL response and ThI-driven Ab secretion with } \\
\text { a significant antitumor response }\end{array}$ & $\begin{array}{l}\text { Almeida } \\
\text { et } \mathrm{al}^{46}\end{array}$ \\
\hline
\end{tabular}

Abbreviations: $\mathrm{PMA}_{\mathrm{SH}}$, poly(methacrylic acid); PLGA, poly-lactic-co-glycolic acid; CEA, carcinoembryonic antigen; PBCA, polybutyl cyanoacrylate; TGF- $\beta$, transforming growth factor beta; Ag, antigen; Ab, antibody; ODN, oligodeoxynucleotide; CLR, C-type lectin receptor; PTX, paclitaxel; AcFu, acetylated fucoidan; GM-CSF, granulocyte macrophage-colony stimulating factor; CTAB, cetyltrimethylammonium bromide; BLP25, MUCI lipopeptide; RFP, red fluorescent protein; NPs, nanoparticles; OVA, ovalbumin; DC, dendritic cell; APC, antigen-presenting cell; IFN- $\gamma$, interferon gamma; IL, interleukin; TLR, Toll-like receptor; ThI, T helper cell type I; MPLA, monophosphoryl lipid A; P-LPS, pleomorphic lipopolysaccharide; DC-SIGN, dendritic cell-specific intercellular adhesion molecule-3-grabbing non-integrin; CTL, cytotoxic T lymphocytes; TNF- $\alpha$, tumor necrosis factor alpha; IgG, immunoglobulin G; TLNP, Taxol-SPLPS nanoparticle.

in size and structure but also, the way they evoke an immune response in the host. This is feasible due to the rapid phagocytosis and processing by APCs as compared with the immune response induced by soluble antigen. Mundargi et al showed the importance of the presence of repetitive structural arrays of antigen on virus-like particles and nanoparticles for induction of an optimum B-cell response. They used the major capsid of the T4 bacteriophage, gp23, as a model peptide. ${ }^{30}$ Antigen-decorated carriers have also been evaluated in an attempt to understand their role in DC activation. Poly- $\gamma$-glutamic acid-based nanoparticles carrying HIV-1 gp120 showed higher uptake by immature DCs. ${ }^{31}$ High expression of costimulatory markers and MHC I was induced on DCs, comparable with stimulation by LPS, ultimately leading to stimulation of functional T-cells. The same can be replicated for activity against tumors by coating the nanoparticles with tumor-specific antigenic peptides. The same group recently showed that poly- $\gamma$-glutamic acid nanoparticles promote fusion of the endosome to the endoplasmic reticulum, resulting in increased antigen loading on $\mathrm{MHC}$ I for cross-presentation of antigen to CD8+ T-cells. ${ }^{32}$

Immunostimulation achieved by antigen-based formulations is sometimes not sufficient, and additional codelivery of adjuvants/TLR ligands can increase the induced immune response. Adjuvant-antigen forms the classical combination to the likes of vaccine, wherein the adjuvant/TLR ligand activates the immune system against the antigen. Drug delivery systems carrying adjuvant-antigen lead to priming of tumor-specific T-cells via DCs. ${ }^{41,42,47}$ Enhanced uptake of the components by DCs and a higher immune response were observed using carrier-based delivery systems as compared with soluble adjuvant/antigen administration.

Nanoparticles/liposomes decorated with ligands or monoclonal antibodies ${ }^{38}$ have been designed to achieve cell specific targeting. In one such study, plasmid coding for CD40 ligand was incorporated into nanoparticles together with adjuvant. ${ }^{37}$ The reduction in nonspecific DC uptake and better stability of TLR ligands within the nanocarriers resulted in a heightened response with lower doses of adjuvant and therefore an improved safety profile. Using DC-SIGN (the DC-specific antibody), it was shown that uptake of $200 \mathrm{~nm}$ nanoparticles by DCs was significantly enhanced as compared with that of $2 \mu \mathrm{m}$ microparticles. ${ }^{48}$ In some studies, nanocarriers coated with TLR ligand ${ }^{35}$ or immunostimulatory peptides, ${ }^{36}$ when administered at the tumor site, activated certain immune cells and reversed the immunosuppressed tumor microenvironment.

Certain polymers used in the formulation of nanoparticles posses immunostimulatory properties themselves, making the use of adjuvants redundant, so are promising candidates for vaccine development. ${ }^{49}$ Nanotoxicology-based research work and study of the properties of nanocarriers, including their antigenicity, adjuvant properties, and inflammatory responses is important for progress in this field. ${ }^{50}$ Chitin and chitosan, along with their derivatives, have demonstrated effective adjuvant properties and are already in use for development of nanoparticles and liposomes. ${ }^{51}$ Wen et al showed a higher humoral immune response when chitosan nanoparticles were coadministered with antigen as compared with administration of antigen in soluble form. ${ }^{52}$ However, results with chitosan NPs were not comparable with the response of positive control, Quil A, a potent adjuvant. On the other hand, the cellular response produced by these nanoparticles exceeded that for Quil A. Chitosan nanoparticles generated potent Th1 and Th2 responses in mouse models. Other nanoparticles developed using poly- $\gamma$-glutamic acid ${ }^{53}$ were found to elicit a potent adjuvant effect and could also deliver antigen. They have been shown to activate splenic DCs by switching on the NFKB and mitogen-activated protein kinase signaling pathways. ${ }^{54}$

Nanocarriers can also act as immune potentiators in the assembly and activation of the multiprotein complexinflammasomes. Inflammasomes are multiprotein complexes 
and are members of intracellular pattern recognition receptors. Activation of one of the members of pattern recognition receptor triggers inflammasome formation, which can further mediate proinflammatory response liberating active cytokines. Phagocytosis of particulate adjuvants such as poly-lactic-coglycolic (PLG) and polystyrene microparticles by DCs drives activation of the NALP3 inflammasome and induces secretion of interleukin (IL)-1 $\beta .{ }^{55}$ When different sizes of particles were tested, smaller ones $(0.43 \mu \mathrm{m}$ and $1 \mu \mathrm{m})$ were readily taken up by DCs, while the larger ones $(10 \mu \mathrm{m}$ and $32 \mu \mathrm{m})$ showed limited uptake. Both small-sized particles were potent inducers of IL- $1 \beta$ secretion, which eventually resulted in enhanced innate and cellular immunity-mediated by DCs. Likewise, the dual efficacy of PLGA NPs as inflammasome activator and antigen carrier has also been studied. ${ }^{56}$

Cytokines play an important role in a number of immune system cascades. Particle-based cytokine immunotherapy can be targeted specifically to tumor tissue, and sustained release leads to a heightened antitumor effect. This approach has been utilized in several studies to administer cytokines (such as IL-2, IL-12, TNF- $\alpha$, and IFN- $\gamma$ ), chemokines, growth factors (eg, granulocyte macrophage-colony stimulating factor) or their combinations to activate various arms of the immune system in the tumor microenvironment, leading to killing of tumor cells. Delivery of cytokines via drug delivery vehicles has been discussed in detail in a recent review. ${ }^{57}$ In one such study, nanoparticles loaded with IL-15 were incubated ex vivo with mouse-derived T-cells, ${ }^{33}$ and when these were reintroduced into mice, T-cell proliferation and survival within the tumor was amplified as compared with soluble cytokine administration. This ex vivo expansion of patient-derived T-cells and their reinfusion has been modified by particle engineers to enhance their potency and is referred to as adoptive cell therapy. Selfgelling alginate solutions that can cross-link in situ following subcutaneous injection can act as reservoir scaffolds. In one such injectable matrix, $\mathrm{CpG}$ oligodeoxynucleotide-loaded microspheres and soluble IL-2 were incorporated. ${ }^{58}$ Cellular infiltration was achieved, creating "vaccination nodes". Antigen-loaded DCs were delivered using the injectable alginate to form in situ matrices. ${ }^{59}$ These scaffolds attracted both host antigen-specific T-cells and DCs, and generated a durable immune response for over a week, making them sound candidates for immunotherapy of solid tumors.

\section{Carrier-based chemoimmunotherapy}

A growing body of evidence suggests that delivering low doses of anticancer drugs along with other types of therapy (such as radiotherapy or immunotherapy) may not solely decrease the toxicity of conventional chemotherapy, and could exert a synergistic effect to eradicate the tumor. ${ }^{9}$ For example, cyclophosphamide eliminates T-regulatory cells, resulting in activation of effector T-cells, and also increases the tumoricidal potential of macrophages and natural killer cells. ${ }^{60}$ Another anticancer drug, paclitaxel, polarizes myeloid-derived suppressor cells towards the M1 macrophage (the desired phenotype for tumor cell killing). Paclitaxel kills tumor cells via apoptosis, leading to availability of tumor antigens. ${ }^{61}$ Various nanocarriers evaluated for clinical administration of antitumor drugs have shown a successful outcome. NPs appear advantageous as carriers of antitumor drug as they promise low systemic toxicity, modified pharmacokinetics, and biodistribution of the encapsulated drug. In previous studies, ${ }^{62,69}$ we evaluated combination chemoimmunotherapy as a prospective strategy against cancer using polymeric nanoparticles. An inhousesynthesized and characterized nontoxic phthalate derivative of LPS, referred to as SP-LPS ${ }^{62,63} / \mathrm{P}_{-} \mathrm{LPS}^{39}$ was used as the TLR-4 agonist. The idea was to activate the suppressed tumor microenvironment using combination chemoimmunotherapy. P-LPS and paclitaxel were coencapsulated in nanoparticles prepared by the oil-in-water emulsion-solvent evaporation method. The in vivo antitumor efficacy of these paclitaxel and P-LPS particles were studied in a B16-F10 melanoma mouse model. Paclitaxel was the drug of choice in our work because it shows cytotoxic activity essentially via the apoptotic pathway ${ }^{64}$ and tumor antigens generated following apoptosis (via apoptotic bodies) can further act as immunomodulators within tumor tissue. To analyze the immune status inside the tumor microenvironment following treatment with the nanoparticles, tumor-infiltrating immune cells were quantified and characterized, and greater infiltration of APCs (macrophages, DCs) and T-cells (markers of tumor regression) was observed. ${ }^{65-67}$ The mean tumor volume in mice treated with paclitaxel and P-LPS was found to be about $40 \%$ less than in animals treated with paclitaxel and P-LPS alone.

\section{Specific role of nanoparticles in immunotherapy}

For effective activation of both the innate and adaptive immune response, optimal delivery of vaccine components (eg, antibody, antigen, adjuvant) via a stable and efficient delivery system is important. Nanocarriers are biodegradable, biocompatible, nanodimensional delivery systems that are capable of carrying the payload in their core, surface, or 
both. They offer several advantages in immunology as well as immunotherapy, and have been extensively reviewed in the last few years. ${ }^{68,69}$

The nanocarrier delivery systems can carry multiple components per nanoparticle each from a wide range of biomolecules such as nucleic acid, protein, or polysaccharides. An interesting example in this regard is a cross-linked, injectable hydrogel carrying DC-attractant chemokines embedded along with particles loaded with immunomodulatory small interfering RNA and plasmid DNA antigen. ${ }^{70}$ Chemokineloaded gels attracted 4-6-fold more immature DCs into the hydrogels than the control which then phagocytosed small interfering RNA-DNA-encapsulated microparticles. Each component was shown to demonstrate its intended function without loss of activity and their sustained release led to a prolonged effect in situ.

Nanoparticles can have a multifunctional role in immunotherapy, including delivery of therapeutic drugs, ${ }^{39}$ imaging agents (for real-time monitoring ${ }^{26}$ ), or ligands/ antibodies $^{38}$ for active targeting. Delivery of drugs in combination with energy (ie, heat, sound, or light) has achieved additional synergistic therapeutic effects. Inorganic nanoparticles of magnetite have been evaluated for use in chemothermoimmunotherapy in models of mouse melanoma. ${ }^{71}$ Magnetite nanoparticles have been developed which cause cancer cells to disintegrate by producing heat shock protein 70 when exposed to an alternating magnetic field, with maximum activity at $43^{\circ} \mathrm{C}$. When coated with N-propionyl-cysteaminylphenol, these particles inhibited the growth of melanoma further by generating cytotoxic free radicals. Tumor growth was retarded and infiltration of CD8+ T-cells was observed at the tumor site, resulting in increased mouse survival time.

Another set of stimuli-responsive carriers deliver their cargo only when triggered, eg, at a particular $\mathrm{pH}$. One such example is ovalbumin-encapsulated microgel particles synthesized with an acid-degradable linker. ${ }^{72}$ This pH-responsive microgel delivers ovalbumin, resulting in higher MHC I antigen presentation by APCs due to degradation of the gel in the mildly acidic conditions present in the phagosomes of these cells. The following sections highlight the specific role of nanoparticles that can activate the immune system against cancer to a greater extent than can immunotherapy applied directly.

\section{Passive and active targeting strategies}

Because of tumor physiology, nanoparticles within a size range of 200-700 $\mathrm{nm}$ tend to accumulate in cancerous tissue after intravenous administration. This nanocarrier-based tumor targeting of drugs is based on the enhanced permeability and retention effect, whereby the distorted capillary endothelium invading the tumor allows easy entry of nanosized molecules from the blood into the tumor microenvironment, and due to the poor lymphatic drainage system in the tumor, the nanocarriers are retained for longer periods. ${ }^{73}$ This nonspecific preferential accumulation of nanoparticles in the tumor milieu forms the basis of passive targeting strategies. The effect of nanoparticle size on immune targeting has been evaluated. ${ }^{74,75}$ It was observed that polystyrene nanoparticles in the size range of $20-200 \mathrm{~nm}$ readily enter the lymphatic capillaries and are retained in the draining lymph node where they are actively taken up by resident DCs. However, nanoparticles in the size range of 500-2,000 nm were mostly taken up by local APCs at the site of injection. Thus, smaller nanoparticle size correlated with higher DC uptake, which in turn led to enhanced activation of the adaptive immune response. Similar results were obtained by Fifis et al, ${ }^{29}$ who found that the optimum size range for nanoparticles used in prophylactic and therapeutic cancer strategies is $40-50 \mathrm{~nm}$.

It has been reported that positively charged nanoparticles are taken up more actively by DCs ${ }^{76}$ but their permeation through tissues is considerably reduced. This is attributed to immobilization of nanoparticles as a result of the negatively charged extracellular matrix. Negatively charged liposomes and nanoparticles on the other hand may be prone to clearance by the reticuloendothelial system or opsonized by the complement system. Small-sized negatively charged nanocarriers decorated with a tumor-specific ligand/antibody ${ }^{38}$ on their surface, enable an increased DC-specific uptake. This strategy is referred to as active targeting. Cell-penetrating peptides have recently been used to facilitate intracellular drug delivery, bypassing the endocytic pathway and in turn increasing the efficiency of cancer immunotherapy. ${ }^{77}$ The pharmacokinetics and biodistribution of these formulations can thus be maneuvered by altering their shape, size, and surface charge, but most importantly by attaching a targeting moiety.

\section{Advantage of nanocarriers over soluble immunotherapeutic formulations}

Pathogens are recognized rapidly by the body's robust immune system, and this has been attributed to the presence of pathogen-associated molecular patterns on their surface. Being similar in size, most nanocarriers are formulated to 
mimic pathogens ${ }^{78}$ encapsulating antigen and coated with an adjuvant. ${ }^{79}$ Pathogen size ranges from $10 \mathrm{~nm}$ to $200 \mathrm{~nm}$ for viruses and from $0.1 \mu \mathrm{m}$ to $8 \mu \mathrm{m}$ for bacteria.

When delivered in soluble form, antigen (ovalbumin) cross-presentation to CD8+ T-cells was found to be low. ${ }^{80}$ However, encapsulation within PLGA nanoparticles increased cellular uptake of albumin and led to 1,000-fold higher T-cell mediated IL-2 secretion than free antigen. Additionally, class I presentation of antigen was extended and continued for up to 96 hours post treatment. It has been demonstrated that poor MHC I presentation by APC occurs following macropinocytosis of soluble antigen, whereas phagocytosis of nanoparticle-encased antigen increases cross-presentation, in turn leading to potent CTL responses. ${ }^{81}$ These cytotoxic cells recognize MHC class I tumor peptide-presenting cancer cells, eventually leading to cancer cell death.

Further, nanocarriers protect the loaded immunotherapeutic (antigen/adjuvant) moiety from possible premature degradation by the biological environment. The most important feature of nanoparticles is their ability to carry a high payload, resulting in a heightened immune response due to prolonged antigen release. A longer duration of antigenic exposure leads to a potent effector and memory response without the need for a booster dose. ${ }^{82}$ However, other studies show better immunization profiles with antigen adsorbed onto the particles as against their encapsulated counterparts. ${ }^{83}$ Experiments in mice showed higher antigen-specific immunoglobulin $\mathrm{G}$ titers with antigen adsorbed on the nanoparticles than with the antigen-encapsulated nanoparticles.

\section{Clinical utility and future directions}

Some clinical studies of nanobased cancer immunotherapies have been successfully completed (Gardasil), but most are either still underway (Ad-ISF35) ${ }^{84}$ or have failed ${ }^{85}$ Phase III clinical trials (Allovectin- $7^{\circledR}$; Vical Incorporated, CA, USA). The aim of existing particle-based cancer immunotherapy is to tailor the release rate of incorporated molecules, achieve specific targeting to the tumor tissue, reduce the side effects observed when the drugs/cytokines are given in soluble form, and ultimately manipulate the immune system to prevent tumor growth (Table 3).

Regardless of their cautiously engineered structure and composition, nanoparticulate drug delivery systems are considered foreign by the body. Interactions between nanoparticles and plasma components, and their clearance and efficacy, must be thoroughly evaluated. ${ }^{86,87}$ "Burst" release of the encapsulated drugs soon after administration by most of the nanocarriers developed thus far may lead to a sudden spike in free drug levels in the blood. Hence, engineering these delivery systems to release their drug in a sustained fashion or in response to a stimulus $^{72}$ could minimize toxicity and drug accumulation at nonspecific sites. Better knowledge of the mechanisms which

Table 3 Clinical status of nanocarrier-based cancer immunotherapies

\begin{tabular}{|c|c|c|}
\hline Clinical carrier-based immunotherapy project & Outcome of study & $\begin{array}{l}\text { Clinical } \\
\text { status }\end{array}$ \\
\hline Doxil $^{\circledR}$ ( $>80$ nm doxorubicin-PEGylated liposomes $)^{96}$ & $\begin{array}{l}\text { Act by complement activation and being used to treat metastatic } \\
\text { ovarian cancer }\end{array}$ & Approved \\
\hline Abraxane $^{\circledR}(\sim 130 \mathrm{~nm} \text { albumin-bound paclitaxel NPs })^{96}$ & $\begin{array}{l}\text { Reduces the hypersensitivity reaction otherwise observed with } \\
\text { paclitaxel alone and being used against NSC lung and breast cancer }\end{array}$ & Approved \\
\hline $\begin{array}{l}\text { Defective adenovirus vector-based NP encoding } \\
\text { engineered CDI54 (Ad-ISF35) }\end{array}$ & $\begin{array}{l}\text { Intranodal injections in patients with chronic lymphocyte leukemia } \\
\text { led to a significant reduction in leukemia cell counts and size of } \\
\text { spleen and lymph nodes. Phase I complete }{ }^{84}\end{array}$ & Phase II \\
\hline $\begin{array}{l}\text { Allovectin- } 7^{\circledR} \text {, a cationic liposome-plasmid complex } \\
\text { wherein the plasmid carries genes coding for HLA-7 } \\
\text { and } \beta 2 \text {-microglobulin to downregulate class I/II MHC } \\
\text { expression reported in several human melanomas }{ }^{97}\end{array}$ & $\begin{array}{l}\text { Phase III clinical trial to evaluate efficacy and safety of Allovectin- } 7^{\circledR} \\
\text { immunotherapy versus first-line chemotherapy (with dacarbazine } \\
\text { or temozolomide) in stage } 3 \text { or } 4 \text { melanoma patients did not } \\
\text { improve either the response rate or overall survival }{ }^{85}\end{array}$ & $\begin{array}{l}\text { Phase III } \\
\text { failed }\end{array}$ \\
\hline TNF- $\alpha$-bound PEGylated gold NPs $(33 \mathrm{~nm})^{98}$ & $\begin{array}{l}\text { Cytokine-dependent systemic side effects were minimized. Tumor- } \\
\text { specific cytotoxicity observed when tested in solid tumors }\end{array}$ & Phase II \\
\hline $\begin{array}{l}\text { Chemoimmunotherapy using PEGylated liposomes } \\
\text { loaded with doxorubicin and IL- } 18^{99}\end{array}$ & $\begin{array}{l}\text { Found to be safe and active in patients with recurrent ovarian } \\
\text { cancer and approved for Phase II study }\end{array}$ & Phase II \\
\hline Cervarix $^{\circledR}$, a bivalent HPVI6/I8 LI VLP'00 & $\begin{array}{l}\text { Induced durable } \mathrm{Ab} \text { response and strong protection against HPV } \\
\text { infections }\end{array}$ & Approved \\
\hline Gardasil $^{\circledR}$ a quadrivalent HPV6/I I/I6/I8 LI VLP100 & $\begin{array}{l}\text { Induced durable } \mathrm{Ab} \text { response and strong protection against HPV } \\
\text { infections }\end{array}$ & Approved \\
\hline
\end{tabular}

Notes: Doxil ${ }^{\circledR}$ (Ortho Biotech, NJ, USA); Abraxane ${ }^{\circledR}$ (Abraxis BioSciences, IL, USA); Allovectin- $7^{\circledR}$ (Vical Incorporated, CA, USA); Cervarix ${ }^{\circledR}$ (GlaxoSmithKline plc, London, UK); Gardasi ${ }^{\circledR}$ (Merck \& Co., Inc., Whitehouse Station, NJ, USA).

Abbreviations: Ab, antibody; NSC, non-small cell; NPs, nanoparticles; PEG, polyethylene glycol; HPV, human papilloma virus; MHC, major histocompatibility complex; VLP, virus-like particles; TNF- $\alpha$, tumor necrosis factor alpha; Ad, adenovirus. 
govern the fate of nanoparticles in the biological milieu could aid in the design of improved nanomedicines and achieve higher clinical safety and efficacy standards.

Advanced technologies such as implant-based products have furthered the drive beyond just nanoscale drug delivery systems. Some of these technologies have already reached the stage of clinical trials. One such project is the development of three-dimensional porous polymeric scaffolds incorporating granulocyte macrophage-colony stimulating factor as the DC attractant, CpG-polyethylenimine nanoparticles as the TLR-9 agonist, and melanoma tumor lysate as the antigen. ${ }^{88,89}$ The three-dimensional scaffolds cause maturation of DCs that home to draining lymph nodes, and these DCs in turn prime naïve T-lymphocytes. This vaccination strategy provided up to $90 \%$ prophylactic as well as therapeutic tumor protection, and has been approved by the US Food and Drug Administration for clinical investigation as an implant vaccine approach..$^{90}$

Virus-like particles are 20-30 nm, virus-resembling nanoparticles, chemically synthesized based on predesigned viral subunits. Because virus-like particles lack genetic material, they are incapable of replication or genetic recombination. ${ }^{13}$ Phase II clinical trials of virus-like particles have shown their potential to generate humoral and cellular immune responses. ${ }^{91}$ When loaded with $\mathrm{CpG}$ oligodeoxynucleotide and melanoma-derived antigen, these virus-like particles induced secretion of proinflammatory cytokines, ie, TNF- $\alpha$, IFN- $\gamma$, and IL-2, via activation of macrophages and CTLs.

Monoclonal antibodies (10-15 nm) are in the same size range as virus-like particles, and can also be considered to fall in the nanomedicine category. They engage surface antigens expressed on tumor cells and their mechanism of immune action involves antibody-dependent cellular phagocytosis and complement-mediated cytotoxicity. ${ }^{92}$ Trastuzumab (anti-HER2) and cetuximab (anti-epidermal growth factor receptor) are two monoclonal antibodies approved for the treatment of breast and colon cancer, respectively. ${ }^{93}$

Monoclonal antibody engineering has led to the development of bispecific antibodies that can target two tumor antigens or another target molecule from the tumor microenvironment. Catumaxomab is one example that has been approved for the treatment of malignant ascites. ${ }^{94}$ Catumaxomab binds to EpCAM (the tumor antigen) and CD3 (the T-cell receptor) via an intact Fc domain. Another variation in monoclonal antibody technology is the bispecific T-cell engager antibody, which can directly stimulate T-cell immunity, and its target is the CD3 molecule and either EpCAM, CD19 (B-lymphocyte antigen), or epidermal growth factor receptor. ${ }^{95}$
Nanocarriers for routine drug delivery are developed so as to escape the immune system while the formulations required for cancer immunotherapy are tailor-made to interact with various arms of the immune system. Hence different sets of parameters need to be adjusted and addressed to achieve specific outcomes.

\section{Conclusion}

With emerging collaborations between immunologists and material scientists, a new range of cancer therapeutics is in development. Carriers such as nanoparticles and liposomes offer an attractive mode of delivery for immunotherapeutics, and are susceptible to degradation in biological fluids. Nanocarriers reduce the systemic cytotoxicity of immunotherapeutic molecules by specific localization in the tumor mass, and a sustained release of these immunotherapeutics leads to prolonged effector and memory immune responses. Drug delivery systems can be tailored to carry a wide range of therapeutics, such as antigen/antibody/cytokines/ligands as single entities or in combination, and encapsulated within the particle or adsorbed onto the surface. These nanocarriers enhance stability and maintain the conformation of the immunomodulators (antigen/antibody). A synergistic effect can be achieved by combination therapy such as chemoimmunotherapy where an anticancer drug can be given for an additional antitumor effect. Polymers having inherent immunomodulatory activity can serve the dual purpose of acting as an immunostimulant particle as well as serving as an antigen/drug carrier. Particlemediated immunotherapy has shown promising outcomes in recent decades, and several research leads are undergoing clinical trials. Process parameters such as the effects of residual solvents (which may interfere with stability of immunomodulators- antigen/antibody/ligands), drying/purification, and sterilization steps should be taken into consideration during particle development for long-term stability and storage. Keeping in mind the translatability of such products, the feasibility of scale-up for large-scale production and cost-effectiveness should not be overlooked. Nanotechnology-based approaches can be adapted to revolutionize pre-existing strategies and can be further maneuvered in design and functionality (including biomarkers for real-time monitoring of in vivo effects) to create safe and effective cancer therapeutics.

\section{Disclosure}

The authors report no conflicts of interest in this work.

\section{References}

1. Kerkar SP, Restifo NP. Cellular constituents of immune escape within the tumor microenvironment. Cancer Res. 2012;72(13):3125-3130. 
2. Baronzio G, Parmar G, Shubina IZ, et al. Update on the challenges and recent advances in cancer immunotherapy. Immunotargets Ther. 2013;2:39-49.

3. Vanneman M, Dranoff G. Combining immunotherapy and targeted therapies in cancer treatment. Nat Rev Cancer. 2012;12(4): 237-251.

4. Dunn GP, Old LJ, Schreiber RD. The three Es of cancer immunoediting. Annu Rev Immunol. 2004;22(4):329-360.

5. Goforth R, Salem AK, Zhu X, et al. Immune stimulatory antigen loaded particles combined with depletion of regulatory T-cells induce potent tumor specific immunity in a mouse model of melanoma. Cancer Immunol Immunother. 2009;58(4):517-530.

6. Ahmad F, Mani J, Kumar P, Haridas S, Upadhyay P, Bhaskar S. Activation of anti-tumor immune response and reduction of regulatory $\mathrm{T}$ cells with Mycobacterium indicus pranii (MIP) therapy in tumor bearing mice. PLoS One. 2011;6(9):e25424.

7. Zitvogel L, Apetoh L, Ghiringhelli F, Kroemer G. Immunological aspects of cancer chemotherapy. Nat Rev Immunol. 2008;8(1):59-73.

8. Shurin MR, Naiditch H, Gutkin DW, Umansky V, Shurin GV. Chemoimmunomodulation: immune regulation by the antineoplastic chemotherapeutic agents. Curr Med Chem. 2012;19(12):1792-1803.

9. Landreneau JP, Shurin MR, Agassandian MV, Keskinov AA, Ma Y, Shurin GV. Immunological mechanisms of low and ultra-low dose cancer chemotherapy. Cancer Microenviron. November 29, 2013. [Epub ahead of print.]

10. Sheng WY, Huang L. Cancer immunotherapy and nanomedicine. Pharm Res. 2011;28(2):200-214.

11. Silva JM, Videira M, Gaspar R, Préat V, Florindo HF. Immune system targeting by biodegradable nanoparticles for cancer vaccines. J Control Release. 2013;168(2):179-199.

12. Reddy ST, van der Vlies AJ, Simeoni E, et al. Exploiting lymphatic transport and complement activation in nanoparticle vaccines. Nat Biotechnol. 2007;25(10):1159-1164.

13. Buonaguro F, Buonaguro L. The application of virus-like particles to human diseases. Expert Rev Vaccines. 2013;12(2):99.

14. Prasad S, Cody V, Saucier-Sawyer JK, et al. Polymer nanoparticles containing tumor lysates as antigen delivery vehicles for dendritic cell-based antitumor immunotherapy. Nanomedicine. 2011;7(1): $1-10$.

15. Vacchelli E, Martins I, Eggermont A, et al. Trial watch: peptide vaccines in cancer therapy. 2012;1(9):1557-1576.

16. van Broekhoven CL, Parish CR, Demangel C, Britton WJ, Altin JG. Targeting dendritic cells with antigen-containing liposomes: a highly effective procedure for induction of antitumor immunity and for tumor immunotherapy. Cancer Res. 2004;64(12):4357-4365.

17. Zhang Z, Tongchusak S, Mizukami Y, et al. Induction of anti-tumor cytotoxic $T$ cell responses through PLGA-nanoparticle mediated antigen delivery. Biomaterials. 2011;32(14):3666-3678.

18. Moon JJ, Suh H, Bershteyn A, et al. Interbilayer-crosslinked multilamellar vesicles as synthetic vaccines for potent humoral and cellular immune responses. Nat Mater. 2011;10(3):243-251.

19. Oda Y, Suzuki R, Otake S, et al. Prophylactic immunization with bubble liposomes and ultrasound-treated dendritic cells provided a four-fold decrease in the frequency of melanoma lung metastasis. $J$ Control Release. 2012;160(2):362-366.

20. Lemke CD, Geary SM, Joshi VB, Salem AK. Antigen-coated poly $\alpha$-hydroxy acid based microparticles for heterologous primeboost adenovirus based vaccinations. Biomaterials. 2013;34(10): 2524-2529.

21. Yoshikawa T, Okada N, Tsujino M, et al. Vaccine efficacy of fusogenic liposomes containing tumor cell-lysate against murine B16BL6 melanoma. Biol Pharm Bull. 2006;29(1):100-104.

22. Palucka K, Banchereau J. Cancer immunotherapy via dendritic cells. Nat Rev Cancer. 2012;12(4):265-277.

23. Klippstein R, Pozo D. Nanotechnology-based manipulation of dendritic cells for enhanced immunotherapy strategies. Nanomedicine. 2010;6(4):523-529.
24. Radford KJ, Tullett KM, Lahoud MH. Dendritic cells and cancer immunotherapy. Curr Opin Immunol. 2014;27C(DC):26-32.

25. Sexton A, Whitney PG, Chong S, et al. A protective vaccine delivery system for in vivo $\mathrm{T}$ cell stimulation using nanoengineered polymer hydrogel capsules. ACS Nano. 2009;3(11):3391-3400.

26. Cho NH, Cheong TC, Min JH, et al. A multifunctional core-shell nanoparticle for dendritic cell-based cancer immunotherapy. Nat Nanotechnol. 2011;6(10):675-682.

27. Prasad S, Cody V, Saucier-Sawyer JK, et al. Polymer nanoparticles containing tumor lysates as antigen delivery vehicles for dendritic cell-based antitumor immunotherapy. Nanomedicine. 2011;7(1): 1-10.

28. Yuba E, Harada A, Sakanishi Y, Watarai S, Kono K. A liposome-based antigen delivery system using $\mathrm{pH}$-sensitive fusogenic polymers for cancer immunotherapy. Biomaterials. 2013;34(12):3042-3052.

29. Fifis T, Gamvrellis A, Crimeen-Irwin B, et al. Size-dependent immunogenicity: therapeutic and protective properties of nano-vaccines against tumors. J Immunol. 2004;173(5):3148-3154.

30. Mundargi RC, Babu VR, Rangaswamy V, Patel P, Aminabhavi TM. $\mathrm{Nano} /$ micro technologies for delivering macromolecular therapeutics using poly(d,1-lactide-co-glycolide) and its derivatives. J Control Release. 2008;125(3):193-209.

31. Akagi T, Wang X, Uto T, Baba M, Akashi M. Protein direct delivery to dendritic cells using nanoparticles based on amphiphilic poly(amino acid) derivatives. Biomaterials. 2007;28(23):3427-3236.

32. Mukai Y, Yoshinaga T, Yoshikawa M, et al. Induction of endoplasmic reticulum-endosome fusion for antigen cross-presentation induced by $\operatorname{poly}(\gamma$-glutamic acid) nanoparticles. J Immunol. 2011;187(12): 6249-6255.

33. Stephan MT, Moon JJ, Um SH, Bershteyn A, Irvine DJ. Therapeutic cell engineering with surface-conjugated synthetic nanoparticles. Nat Med. 2010;16(9):1035-1041.

34. Schneider T, Becker A, Ringe K, Reinhold A, Firsching R, Sabel BA. Brain tumor therapy by combined vaccination and antisense oligonucleotide delivery with nanoparticles. J Neuroimmunol. 2008;195(1-2):21-27.

35. Lin AY, Mattos Almeida JP, Bear A, et al. Gold nanoparticle delivery of modified $\mathrm{CpG}$ stimulates macrophages and inhibits tumor growth for enhanced immunotherapy. PLoS One. 2013;8(5):e63550.

36. Clawson C, Huang CT, Futalan D, et al. Delivery of a peptide via poly(D,L-lactic-co-glycolic) acid nanoparticles enhances its dendritic cell-stimulatory capacity. Nanomedicine. 2010;6(5):651-661.

37. Stone GW, Barzee S, Snarsky V, et al. Nanoparticle-delivered multimeric soluble CD40L DNA combined with Toll-like receptor agonists as a treatment for melanoma. PLoS One. 2009;4(10):e7334.

38. Tacken PJ, Zeelenberg IS, Cruz LJ, et al. Targeted delivery of TLR ligands to human and mouse dendritic cells strongly enhances adjuvanticity. Blood. 2011;118(26):6836-6844.

39. Roy A, Singh MS, Upadhyay P, Bhaskar S. Nanoparticle mediated codelivery of paclitaxel and a TLR-4 agonist results in tumor regression and enhanced immune response in the tumor microenvironment of a mouse model. Int J Pharm. 2013;445(1-2):171-180.

40. Woo K, Jeong D, Na K. Doxorubicin loading fucoidan acetate nanoparticles for immune and chemotherapy in cancer treatment. Carbohydr Polym. 2013;94(2):850-856.

41. Mueller M, Schlosser E, Gander B, Groettrup M. Tumor eradication by immunotherapy with biodegradable PLGA microspheres - an alternative to incomplete Freund's adjuvant. Int J Cancer. 2011;129(2): 407-416.

42. Schlosser E, Mueller M, Fischer S, et al. TLR ligands and antigen need to be coencapsulated into the same biodegradable microsphere for the generation of potent cytotoxic T lymphocyte responses. Vaccine. 2008;26(13):1626-1637.

43. Heffernan MJ, Kasturi SP, Yang SC, Pulendran B, Murthy N. The stimulation of CD8 $+\mathrm{T}$ cells by dendritic cells pulsed with polyketal microparticles containing ion-paired protein antigen and poly(inosinic acid)-poly(cytidylic acid). Biomaterials. 2009;30(5): 910-918. 
44. Elamanchili P, Lutsiak CM, Hamdy S, Diwan M, Samuel J. "Pathogenmimicking" nanoparticles for vaccine delivery to dendritic cells. J Immunother. 2007;30(4):378-395.

45. Beaudette TT, Bachelder EM, Cohen JA, et al. In vivo studies on the effect of co-encapsulation of CpG DNA and antigen in acid-degradable microparticle. 2009;6(4):1160-1169.

46. Almeida JPM, Figueroa ER, Drezek RA. Gold nanoparticle mediated cancer immunotherapy. Nanomedicine. 2014;10(3):503-514.

47. Lee IH, Kwon HK, An S, et al. Imageable antigen-presenting gold nanoparticle vaccines for effective cancer immunotherapy in vivo. Angew Chem Int Ed Engl. 2012;51(35):8800-8805.

48. Cruz LJ, Tacken PJ, Fokkink R, et al. Targeted PLGA nano- but not microparticles specifically deliver antigen to human dendritic cells via DC-SIGN in vitro. J Control Release. 2010;144(2):118-126.

49. Allsopp CE, Plebanski M, Gilbert S, et al. Comparison of numerous delivery systems for the induction of cytotoxic T lymphocytes by immunization. Eur J Immunol. 1996;26(8):1951-1959.

50. Dobrovolskaia MA, McNeil SE. Immunological properties of engineered nanomaterials. Nat Nanotechnol. 2007;2(8):469-478.

51. Li X, Min M, Du N, et al. Chitin, chitosan, and glycated chitosan regulate immune responses: the novel adjuvants for cancer vaccine. Clin Dev Immunol. 2013;2013:387023.

52. Wen ZS, Xu YL, Zou XT, Xu ZR. Chitosan nanoparticles act as an adjuvant to promote both Th1 and Th2 immune responses induced by ovalbumin in mice. Mar Drugs. 2011;9(6):1038-1055.

53. Uto T, Akagi T, Yoshinaga K, Toyama M, Akashi M, Baba M. The induction of innate and adaptive immunity by biodegradable poly $(\gamma-$ glutamic acid) nanoparticles via a TLR4 and MyD88 signaling pathway. Biomaterials. 2011;32(22):5206-5212.

54. Uto T, Wang X, Sato K, et al. Targeting of antigen to dendritic cells with poly(gamma-glutamic acid) nanoparticles induces antigenspecific humoral and cellular immunity. J Immunol. 2007;178(5): 2979-2986.

55. Sharp FA, Ruane D, Claass B, et al. Uptake of particulate vaccine adjuvants by dendritic cells activates the NALP3 inflammasome. Proc Natl Acad Sci U S A. 2009;106(3):870-875.

56. Demento SL, Eisenbarth SC, Foellmer HG, et al. Inflammasomeactivating nanoparticles as modular systems for optimizing vaccine efficacy. Vaccine. 2009;27(23):3013-3021.

57. Christian DA, Hunter CA. Particle-mediated delivery of cytokines for immunotherapy. Immunotherapy. 2012;4(4):425-441.

58. Hori Y, Winans AM, Irvine DJ. Modular injectable matrices based on alginate solution/microsphere mixtures that gel in situ and co-deliver immunomodulatory factors. Acta Biomater. 2009;5(4):969-982.

59. Hori Y, Winans AM, Huang CC, Horrigan EM, Irvine DJ. Injectable dendritic cell-carrying alginate gels for immunization and immunotherapy. Biomaterials. 2008;29(27):3671-3682.

60. Sistigu A, Viaud S, Chaput N, Bracci L, Proietti E, Zitvogel L. Immunomodulatory effects of cyclophosphamide and implementations for vaccine design. Semin Immunopathol. 2011;33(4):369-383.

61. Shurin GV, Tourkova IL, Kaneno R, Shurin MR. Chemotherapeutic agents in noncytotoxic concentrations increase antigen presentation by dendritic cells via an IL-12-dependent mechanism. J Immunol. 2009;183(1):137-144.

62. Roy A, Singh MS, Upadhyay P, Bhaskar S. Combined chemoimmunotherapy as a prospective strategy to combat cancer: a nanoparticle based approach. Mol Pharm. 2010;7(5):1778-1788.

63. Roy A, Chandra S, Mamilapally S, Upadhyay P, Bhaskar S. Anticancer and immunostimulatory activity by conjugate of paclitaxel and non-toxic derivative of LPS for combined chemo-immunotherapy. Pharm Res. 2012;29(8):2294-2309.

64. Hsiao JR, Leu SF, Huang BM. Apoptotic mechanism of paclitaxelinduced cell death in human head and neck tumor cell lines. J Oral Pathol Med. 2009;38(2):188-197.

65. Pagès F, Galon J, Dieu-Nosjean MC, Tartour E, Sautès-Fridman C, Fridman WH. Immune infiltration in human tumors: a prognostic factor that should not be ignored. Oncogene. 2010;29(8):1093-1102.
66. Hagemann T, Lawrence T, Mcneish I, et al. "Re-educating" tumorassociated macrophages by targeting NF-kappaB. J Exp Med. 2008;205(6):1261-1268.

67. Wang B, Li Q, Qin L, Zhao S, Wang J, Chen X. Transition of tumor-associated macrophages from MHC class II high to MHC class II low mediates tumor progression in mice. BMC Immunol. 2011;12(1):43.

68. Serda RE. Particle platforms for cancer immunotherapy. Int $J$ Nanomedicine. 2013;8:1683-1696.

69. Smith DM, Simon JK, Baker JR. Applications of nanotechnology for immunology. Nat Rev Immunol. 2013;13(8):592-605.

70. Singh A, Suri S, Roy K. In-situ crosslinking hydrogels for combinatorial delivery of chemokines and siRNA-DNA carrying microparticles to dendritic cells. Biomaterials. 2009;30(28):5187-5200.

71. Takada T, Yamashita T, Sato M, et al. Growth inhibition of re-challenge B16 melanoma transplant by conjugates of melanogenesis substrate and magnetite nanoparticles as the basis for developing melanoma-targeted chemothermo-immunotherapy. J Biomed Biotechnol. 2009;2009:457936.

72. Murthy $\mathrm{N}, \mathrm{Xu} \mathrm{M}$, Schuck S, Kunisawa J, Shastri N, Fréchet JM. A macromolecular delivery vehicle for protein-based vaccines: aciddegradable protein-loaded microgels. Proc Natl Acad Sci U S A. 2003;100(9):4995-5000.

73. Maeda $H$. The enhanced permeability and retention (EPR) effect in tumor vasculature: the key role of tumor-selective macromolecular drug targeting. Adv Enzyme Regul. 2001;41(00):189-207.

74. Manolova V, Flace A, Bauer M, Schwarz K, Saudan P, Bachmann MF. Nanoparticles target distinct dendritic cell populations according to their size. Eur J Immunol. 2008;38(5):1404-1413.

75. Xiang SD, Scholzen A, Minigo G, et al. Pathogen recognition and development of particulate vaccines: does size matter? Methods. 2006;40(1):1-9.

76. Foged C, Brodin B, Frokjaer S, Sundblad A. Particle size and surface charge affect particle uptake by human dendritic cells in an in vitro model. Int J Pharm. 2005;298(2):315-322.

77. Wang HY, Wang R. Enhancing cancer immunotherapy by intracellular delivery of cell-penetrating peptides and stimulation of pattern-recognition receptor signaling. Adv Immunol. 2012;114:151-176.

78. Moon JJ, Huang B, Irvine DJ. Engineering nano- and microparticles to tune immunity. Adv Mater. 2012;24(28):3724-3746.

79. Little SR. Reorienting our view of particle-based adjuvants for subunit vaccines. Proc Natl Acad Sci U S A. 2012;109(4):999-1000.

80. Shen H, Ackerman AL, Cody V, et al. Enhanced and prolonged cross-presentation following endosomal escape of exogenous antigens encapsulated in biodegradable nanoparticles. Immunology. 2006;117(1): 78-88.

81. Harding CV, Song R. Phagocytic processing of exogenous particulate antigens. J Immunol. 1994;153(11):4925-4933.

82. Waeckerle-Men Y, Allmen EU, Gander B, et al. Encapsulation of proteins and peptides into biodegradable poly(D,L-lactide-co-glycolide) microspheres prolongs and enhances antigen presentation by human dendritic cells. Vaccine. 2006;24(11):1847-1857.

83. Florindo HF, Pandit S, Lacerda L, Gonçalves LM, Alpar HO, Almeida AJ. The enhancement of the immune response against $\mathrm{S}$. equi antigens through the intranasal administration of poly-epsilon-caprolactonebased nanoparticles. Biomaterials. 2009;30(5):879-891.

84. Melo-Cardenas J, Urquiza M, Kipps TJ, Castro JE. Intratumoral delivery of CD154 homolog (Ad-ISF35) induces tumor regression: analysis of vector biodistribution, persistence and gene expression. Cancer Gene Ther. 2012;19(5):336-344.

85. ClinicalTrials.gov. A Phase 3 pivotal trial comparing Allovectin- $7^{\circledR}$ alone vs chemotherapy alone in patients with stage 3 or stage 4 melanoma. Available from: http://clinicaltrials.gov/show/NCT00395070. Accessed May 13, 2014

86. Karmali PP, Simberg D. Interactions of nanoparticles with plasma proteins: implication on clearance and toxicity of drug delivery systems. Expert Opin Drug Deliv. 2011;8(3):343-357.

87. Alexis F, Pridgen E, Molnar LK, Farokzhad OC. Factors affecting the clearance and biodistribution of polymeric nanoparticles. Mol Pharm. 2008;5(4):505-515. 
88. Ali OA, Huebsch N, Cao L, Mooney DJ. Infection-mimicking materials to program dendritic cells in situ. Nat Mater. 2009;8(2):151-158.

89. Ali OA, Verbeke C, Johnson C, et al. Identification of immune factors regulating antitumor immunity using polymeric vaccines with multiple adjuvants. Cancer Res. 2014;74(6):1670-1681.

90. Harvard Gazette. Cancer vaccine begins Phase I clinical trials. Available from: http://news.harvard.edu/gazette/story/2013/09/cancer-vaccinebegins-phase-i-clinical-trials/. Accessed May 13, 2014.

91. Goldinger SM, Dummer R, Baumgaertner P, et al. Nano-particle vaccination combined with TLR-7 and -9 ligands triggers memory and effector $\mathrm{CD}^{+}$T-cell responses in melanoma patients. Eur J Immunol. 2012;42(11):3049-3061.

92. Weiner LM, Murray JC, Shuptrine CW. Minireview antibody-based immunotherapy of cancer. Cell. 2012;148(6):1081-1084.

93. Curiel TJ, editor. Cancer Immunotherapy. New York, NY, USA: Springer New York; 2013.

94. Tsikouras P, Tsagias N, Pinidis P, et al. The contribution of catumaxomab in the treatment of malignant ascites in patients with ovarian cancer: a review of the literature. Arch Gynecol Obstet. 2013;288(3): $581-585$.
95. Wickramasinghe D. Tumor and T cell engagement by BiTE. Discov Med. 2013;16(88):149-152.

96. Park K. Facing the truth about nanotechnology in drug delivery. ACS Nano. 2013;7(9):7442-7447.

97. Bedikian AY, Del Vecchio M. Allovectin-7 therapy in metastatic melanoma. Expert Opin Biol Ther. 2008;8(6):839-844.

98. CytImmune Sciences, Inc. Aurimune ${ }^{\mathrm{TM}}$ (CYT-6091). Available from: http://www.cytimmune.com/go.cfm?do=page.viewandpid=26. Accessed May 13, 2014.

99. Simpkins F, Flores A, Chu C, et al. Chemoimmunotherapy using PEGylated liposomal doxorubicin and interleukin-18 in recurrent ovarian cancer: a Phase I dose-escalation study. Cancer Immunol Res. 2013;1(3):168-178.

100. Schiller JT, Castellsagué X, Garland SM. A review of clinical trials of human papillomavirus prophylactic vaccines. Vaccine. 2012; 30 Suppl 5:F123-F138.

\section{Publish your work in this journal}

ImmunoTargets and Therapy is an international, peer-reviewed open access journal focusing on the immunological basis of diseases, potential targets for immune based therapy and treatment protocols employed to improve patient management. Basic immunology and physiology of the immune system in health, and disease will be also covered. In addition, the journal will focus on the impact of manage-

\section{Dovepress}

ment programs and new therapeutic agents and protocols on patient perspectives such as quality of life, adherence and satisfaction. The manuscript management system is completely online and includes a very quick and fair peer-review system, which is all easy to use. Visit http://www.dovepress.com/testimonials.php to read real quotes from published authors.

Submit your manuscript here: http://www.dovepress.com/immunotargets-and-therapy-journal 